\title{
Bile acid activated receptors are targets for regulation of integrity of gastrointestinal mucosa
}

\author{
Eleonora Distrutti - Luca Santucci - Sabrina Cipriani - Barbara Renga • \\ Elisabetta Schiaroli • Patrizia Ricci • Annibale Donini · Stefano Fiorucci
}

Received: 18 December 2014/ Accepted: 9 January 2015/Published online: 24 February 2015

(C) Springer Japan 2015

\begin{abstract}
Bile acids are the end product of cholesterol metabolism. Synthesized in the liver, primary bile acids are secreted by hepatocytes and are transformed by intestinal microbiota into secondary bile acids. In addition to their role in cholesterol and lipid absorption, bile acids act as signaling molecules activating a family of nuclear and G-protein-coupled receptors collectively known as bile acid activated receptors (BARs). These receptors are expressed at high density in enterohepatic tissues, but their expression occurs throughout the body and their activation mediates regulatory functions of bile acids on lipids and glucose metabolism and immunity. In the gastrointestinal tract, BARs maintain intestinal integrity, and their deletion makes the intestine more susceptible to the damage caused by acetylsalicylic acid and nonsteroidal anti-inflammatory drugs (NSAIDs). Deficiency in farnesoid $\mathrm{X}$ receptor and G-protein-coupled bile acid receptor 1 genes alters the expression/activity of cystathione $\gamma$-lyase and endothelial
\end{abstract}

Part of this review was presented at the 4th International Forum of the 100th General Meeting of the Japanese Society of Gastroenterology.

E. Distrutti

Azienda Ospedaliera di Perugia, Perugia, Italy

L. Santucci

Azienda Unita' Sanitaria Locale Umbria 2, Perugia, Italy

S. Cipriani · E. Schiaroli

Dipartimento di Medicina, Università degli Studi di Perugia,

Perugia, Italy

B. Renga $\cdot$ P. Ricci $\cdot$ A. Donini $\cdot$ S. Fiorucci $(\square)$

Sezione di Gastroenterologia, Dipartimento di Scienze

Chirurgiche e Biomediche, Nuova Facoltà di Medicina e

Chirurgia, Università di Perugia, Edificio B-Piano III-Via

Gambuli,1, S. Andrea delle Fratte-Perugia, 06132 Perugia, Italy

e-mail: fiorucci@unipg.it; Stefano.fiorucci@unipg.it nitric oxide synthase, two genes involved in the synthesis of hydrogen sulfide and nitric oxide, i.e., two gaseous mediators that have been shown to be essential in maintaining the intestinal homeostasis. In addition, farnesoid $\mathrm{X}$ receptor regulates the expression of transporters required for secretion of phospholipid by hepatocytes. Because phospholids attenuate intestinal injury caused by acetylsalicylic acid and NSAIDs, BAR agonism could be exploited to protect the intestinal mucosa against injury caused by anti-inflammatory medications. This approach might be useful in the prevention of so-called NSAID enteropathy, a common clinical condition occurring in long-term users of NSAIDs, which is not effectively prevented either by cotreatment with proton pump inhibitors or by the use of coxibs.

$\begin{array}{ll}\text { Abbreviations } \\ \text { ASA } & \text { Acetylsalicylic acid } \\ \text { BAR } & \text { Bile acid activated receptors } \\ \text { CA } & \text { Cholic acid } \\ \text { cAMP } & \text { Cyclic AMP } \\ \text { CDCA } & \text { Chenodeoxycholic acid } \\ \text { CGRP } & \text { Calcitonin-gene-related peptide } \\ \text { COX } & \text { Cyclooxygenase } \\ \text { CSE } & \text { Cystathionine } \gamma \text {-lyase } \\ \text { CYP27A1 } & \text { Cytochrome P450, family 27, subfamily A, } \\ & \text { polypeptide 1 } \\ \text { CYP7A1 } & \text { Cytochrome P450, family 7, subfamily A, } \\ & \text { polypeptide 1 } \\ \text { DCA } & \text { Deoxycholic acid } \\ \text { eNOS } & \text { Endothelial NO synthase } \\ \text { FGF } & \text { Fibroblast growth factor } \\ \text { FXR } & \text { Farnesoid X receptor } \\ \text { GLP-1 } & \text { Glucagon-like peptide 1 }\end{array}$




$\begin{array}{ll}\text { GP-BAR1 } & \text { G-protein-coupled bile acid receptor } 1 \\ \text { 5-HT } & \text { 5-Hydroxytryptamine } \\ \text { LCA } & \text { Litocholic acid } \\ \text { mRNA } & \text { Messenger RNA } \\ \text { MRP } & \text { Multidrug-resistance-associated protein } \\ \text { NOS } & \text { NO synthase } \\ \text { NR } & \text { Nuclear receptor } \\ \text { NSAID } & \text { Nonsteroidal anti-inflammatory drug } \\ \text { OST } & \text { Organic solute transporter } \\ \text { PG } & \text { Prostaglandin } \\ \text { PGES } & \text { Prostaglandin E synthase } \\ \text { PPI } & \text { Proton punp inhibitor } \\ \text { TNF } & \text { Tumor necrosis factor }\end{array}$

\section{Introduction}

Bile acids, the end product of cholesterol metabolism (Fig. 1), are the major component of bile. They are amphipathic molecules essential for solubilization, absorption, and metabolism of lipids and fat-soluble vitamins [1]. The principal human bile acids are the primary bile acids cholic acid (CA) and chenodexycholic acid (CDCA), their glycine (in humans) and taurine (in rodents) conjugates, and the secondary bile acids deoxycholic acid (DCA) and lithocolic acid (LCA). Bile acids are synthesized in the liver (Fig. 1) from cholesterol by a pathway consisting of a cascade of 15 reactions. The main bile acid biosynthetic pathway (neutral or classic) is initiated by cholesterol $7 \alpha$-hydroxylase (also known as cytochrome P450, family 7, subfamily A, polypeptide 1, CYP7A1) (reviewed in [1-3]). The alternative (or acidic) pathway is initiated by sterol 27-hydroxylase (also known as cytochrome P450, family 27 , subfamily A, polypeptide 1, CYP27A1). In humans, the classic pathway produces CA and CDCA in roughly equal amounts, whereas the acidic pathway produces mainly CDCA. In the classic pathway, sterol $12 \alpha$-hydroxylase is involved in the synthesis of CA and controls the ratio of CA to CDCA [1]. In the small intestine, bile acids are subjected to deamidation and $7 \alpha$-dehydroxylation by the intestinal microbiota, yielding the secondary bile acids DCA and LCA (Fig. 1), which are then absorbed in the distal ileum, completing the enterohepatic circulation. The hydrophilichydrophobic balance of each bile acid accounts for a large part for their role in nutrient absorption. The bile acid molecule has a convex face that is hydrophobic because of methyl groups and a hydrophilic face with hydroxyl groups. The hydrophilicity index depends on the number and position of $\mathrm{OH}$ groups, and whether amidation of the lateral chain is with glycine or taurine. Bile acids conjugated with taurine are more hydrophilic than those conjugated with glycine, and trihydroxylated bile acids are more hydrophilic than dihydroxylated bile acids. Bile acids with a high hydrophilicity index (ursodeoxycholic acid and CA) are choleretic and less toxic to cells, whereas hydrophobic bile acids (CDCA, DCA, and LCA) are toxic at concentrations of $200 \mu \mathrm{M}$ and above.

\section{Bile acid activated receptors}

Similarly to other cholesterol metabolites, bile acids are signaling molecules. Several major signaling networks are activated by bile acids [1-5]. Thus, bile acids are known ligands for at least four members of the nuclear receptor (NR) superfamily (Figs. 1, 2), i.e., farnesoid X receptor (FXR; also known as NR1H4), constitutive androstane receptor (also known as NR1H3), pregnane $\mathrm{X}$ receptor (also known as NR1H2) and vitamin D receptor (also known as NR1H1) [1-6]. In addition, secondary bile acids activate G-protein-coupled receptors, including G-proteincoupled bile acid receptor 1 (GP-BAR1; also known as M-BAR, TGR5, or BG37) and muscarinic receptors [1-6]. Further, primary and secondary bile acids activate voltageand calcium-gated potassium channels (BKCa or KCa1.1). In addition, bile acids interact with tyrosine kinase coupled receptors, causing the transactivation of epidermal growth factor receptor (Fig. 2). Each bile acid interacts with more than one receptor, and this promiscuity supports the fact that each bile acid exerts a variety of pathophysiological and pharmacological activities.

\section{FXR, a bile acid sensor}

FXR is a bile acid sensor in the liver and intestine. FXR binds to specific DNA response elements as a heterodimeric complex with retinoid $\mathrm{X}$ receptor. The FXRretinoid $\mathrm{X}$ receptor heterodimer binds DNA sequences on target genes composed of two inverted repeats separated by one nucleotide, and can be activated by ligands for both receptors (bile acids and/or 9-cis-retinoic acid). On ligand binding, FXR undergoes conformational changes to release corepressors such as NCor (a nuclear corepressor) and recruits coactivators such as steroid receptor coactivator 1 , protein arginine methyltransferase 1 , coactivatorassociated arginine methyltransferase 1, peroxisome-proliferator-activated receptor $\gamma$ coactivator $1 \alpha$, and vitamin D receptor interacting protein 205 [1-6]. In hepatocytes, a rise in intracellular bile acid concentrations results in the transcriptional activation of FXR (Fig. 3). One FXR target gene is the small heterodimer partner, an atypical NR that lacks a ligand-binding domain, and that dimerizes with and inactivates both liver receptor homolog 1 and liver $\mathrm{X}$ receptor $\alpha$, resulting in a decrease in CYP7A1 expression and inhibition of bile acid synthesis through the neutral pathway [7, 8]. In addition, FXR ligands 


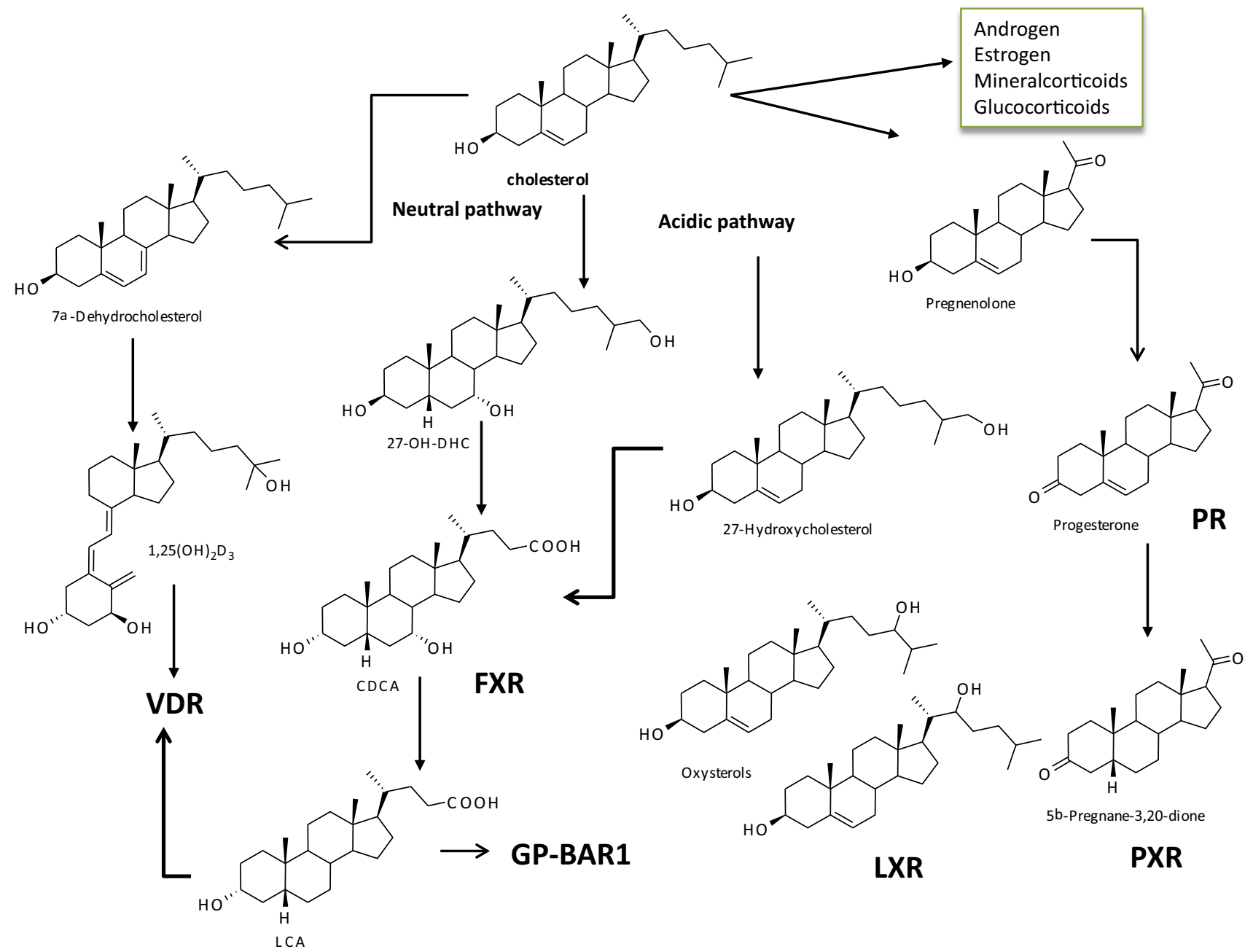

Fig. 1 Cholesterol metabolism generates bioactive ligands for nuclear and G-protein-coupled receptors. $C D C A$ chenodexycholic acid, FXR farnesoid X receptor, GP-BARl G-protein-coupled bile

negatively regulate basolateral bile acid uptake by hepatocytes via repression of $\mathrm{Na}^{+} /$taurocholate cotransporting polypeptide, organic anion transporting polypeptide 1 , and organic anion transporting polypeptide 4 , and stimulate the overall gene expression of both canalicular [multidrug-resistance-associated protein (MRP) 3 and bile salt export pump] and alternative basolateral efflux transporters [MRP3, MRP4, organic solute transporter (OST) $\alpha$, and OST $\beta$ ). Additionally, in hepatocytes, FXR activation increases the expression of genes encoding proteins involved in bile acid detoxification: $C Y P 3 A 4$, members of the UDP glycosyltransferase 2 family, polypeptide B family, and Sult2al [9, 10]. In the intestine, FXR activation modulates the expression of specific transporters by repressing human apical sodium bile acid transporter and inducing basolateral OSTs (OST $\alpha$ and OST $\beta$ ). Importantly, activation of intestinal FXR increases the expression of and causes the release of fibroblast growth acid receptor 1, $L C A$ lithocolic acid, $L X R$ liver $\mathrm{X}$ receptor, 27- $\mathrm{OH}$ $D H C$ 27-dihydroxycholesterol, $P R$ progesterone receptor, $P X R$ pregnane $\mathrm{X}$ receptor, $V D R$ vitamin $\mathrm{D}$ receptor

factor (FGF)-15 and FGF-19 in humans [11, 12]. FGF-15, by binding to type 4 FGF receptor, represses both human apical sodium bile acid transporter in enterocytes and CYP7A1 in hepatocytes. Thus, FXR regulates CYP7A1 by modalities dependent on FGF-15 and small heterodimer partner (Fig. 3). Additionally, FXR activation in the kidney in mice induces the expression/activity of MRP2 and OST $\alpha /$ OST $\beta$ on the basolateral surface of renal tubular cells, increasing the overall elimination capacity of potentially toxic bile acids from the body (for reviews, see $[2,3])$.

\section{G-protein-coupled bile acid receptor 1}

GP-BAR1 is a G-protein-coupled receptor mainly expressed in the intestine. Because a detailed description of the metabolic effects fall outside the aim of this review, 


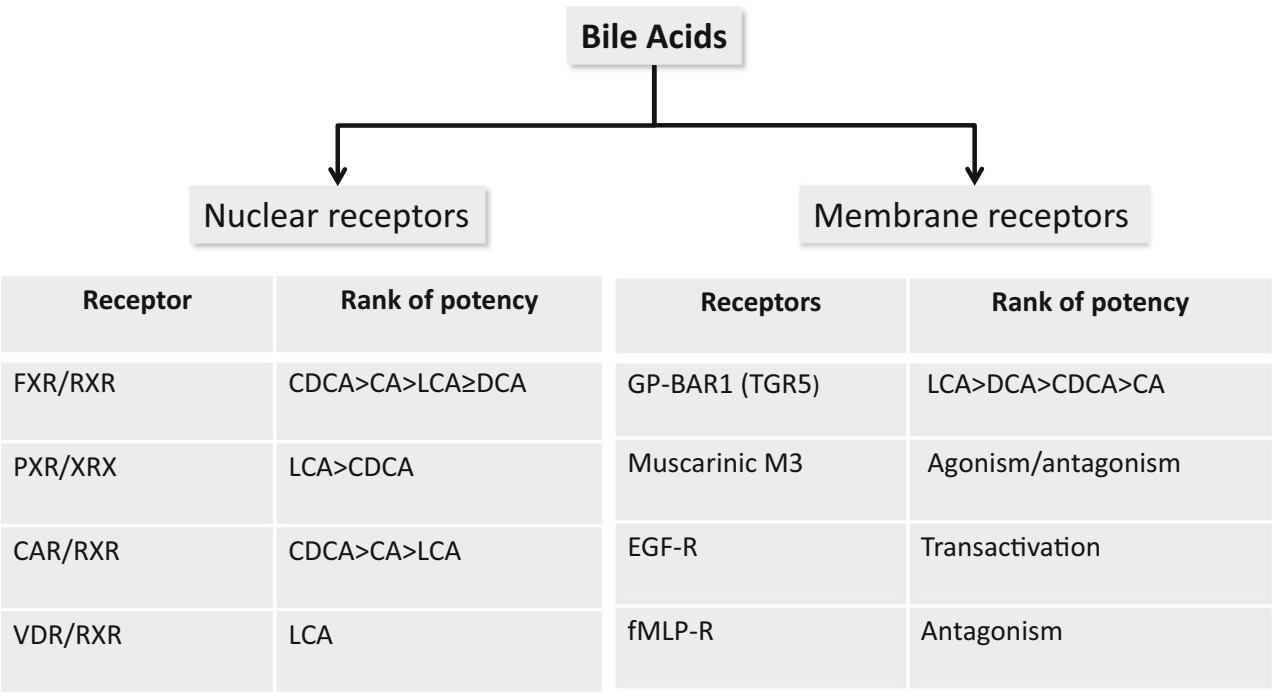

Fig. 2 Bile acid activated receptors and their endogenous ligands. $C A$ cholic acid, $C A R$ constitutive androstane receptor, $C D C A$ chenodeoxycholic acid, DCA deoxycholic acid, $E G F-R$ epidermal growth factor receptor, $f M L P-R$ formylmethionylleucylphenylalanine

receptor, $F X R$ farnesoid $\mathrm{X}$ receptor, GP-BARl G-protein-coupled bile acid receptor 1, $L C A$ lithocolic acid, $P X R$ pregnane $\mathrm{X}$ receptor, $R X R$ retinoid $\mathrm{X}$ receptor, $V D R$ vitamin $\mathrm{D}$ receptor, $X R X \mathrm{X}$ receptor $\mathrm{X}$

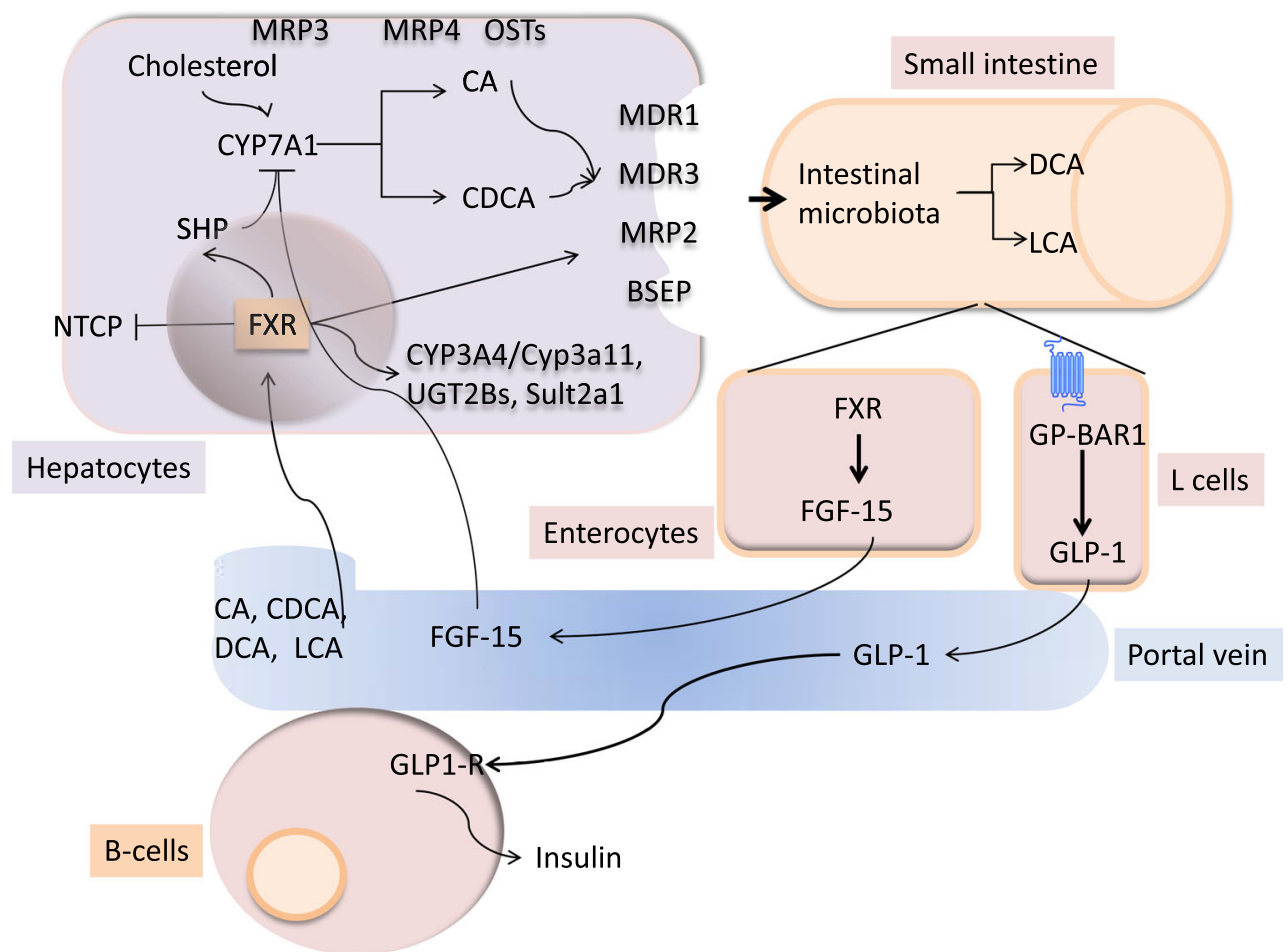

Fig. 3 Enterohepatic network of bile acid activated receptors. During their enterhepatic circulation, bile acids activate a number of receptors and release mediators that act on additional targets in the intestine and liver. BSEP bile salt export pump, $C A$ cholic acid, $C D C A$ chenodeoxycholic acid, CYP3A4 cytochrome P450, family 3, subfamily A, polypeptide 4, Cyp3a11 cytochrome P450, family 3, subfamily A, polypeptide 2, CYP7A1 cytochrome P450, family 7, subfamily A, polypeptide $1, D C A$ deoxycholic acid $F G F-15$ fibroblast growth factor $15, F X R$ farnesoid $\mathrm{X}$ receptor, GLP-1 glucagon-like peptide $1, G L P 1-R$ glucagon-like peptide 1 receptor, GP-BARl
G-protein-coupled bile acid receptor 1, LCA lithocolic acid, MDR1 multidrug resistance protein $1, M D R 3$ multidrug resistance protein 3, $M R P 2$ multidrug-resistance-associated protein 2, MRP3 multidrugresistance-associated protein 3, MRP4 multidrug-resistance-associated protein 4, NTCP Na${ }^{+}$/taurocholate cotransporting polypeptide, OST organic solute transporter, SHP small heterodimer partner, Sult2a1 sulfotransferase family, cytosolic, 2A, dehydroepiandrosterone-preferring, member $1, U G T 2 B$ UDP glycosyltransferase 2 family, polypeptide B 
readers are referred to our previous reviews on GP-BAR1 $[2,3]$ and Fig. 3. In addition, GP-BAR1 exerts physiological functions in regulating intestinal motility and secretions $[13,14]$. In the gastrointestinal tract, GP-BAR1 immunoreactivities have been detected in myenteric and submucosal neurons and in nerve plexuses. In these neurons, GP-BAR1 colocalizes with NO synthase (NOS) in the inhibitory motor neurons of the myenteric plexus of the large intestine [14]. Consistent with this colocalization, activation of GP-BAR1 by DCA, a GP-BAR1 agonist, inhibited spontaneous, phasic contractions of isolated segments of colonic longitudinal muscle by a neurogenic and nitrergic mechanism. Luminal administration of DCA also delays gastric emptying and small intestinal transit in mice [14].

Studies of colonic peristalsis, transit, and defecation in mice with a loss or gain (transgenic) of GP-BAR1 function have revealed a role for this receptor in regulating colonic motility and defecation [15]. In addition to expression in inhibitory motor neurons, GP-BAR1 immunoreactivity in the mouse colon colocalizes with two transmitters of the afferent limb of the peristaltic reflex: 5-hydroxytryptamine (5-HT) in enterochromaffin cells and calcitonin-gene-related peptide (CGRP) in intrinsic primary afferent neurons. The mucosal application of physiological concentrations of DCA and LCA (less than $100 \mu \mathrm{M}$ ) to a flat sheet preparation of mouse colon evokes an ascending contraction and descending relaxation of circular muscle, consistent with stimulation of peristalsis, and concomitantly stimulates release of the peristaltic transmitters 5-HT and CGRP. GP-BAR1 deletion abolishes these effects, and antagonism of 5-HT $\mathrm{H}_{4}$ receptors and CGRP receptors blocks GP-BAR1evoked peristalsis, consistent with the localization of GPBAR1 in enterochromaffin cells and intrinsic primary afferent neurons [14-16]. Considered together, these results suggest that GP-BAR1 mediates the prokinetic actions of bile acids in the colon and that the receptor is required for normal defecation. Genetic variations in GPBAR1, particularly single-nucleotide polymorphism (rs11554825), have been proposed to contribute to altered small bowel and colonic transit [17]. An analysis of the association between GP-BAR1 single-nucleotide polymorphism rs 11554825 and symptom phenotypes suggests that genetic variations of GP-BAR1 could alter small bowel and colonic transit in patients with lower functional gastrointestinal tract disorders, in particular, the diarrheapredominant variant of irritable bowel syndrome.

Another important effect of GP-BAR1 in the small intestine is the regulation of glucagon-like peptide 1 (GLP1), a hormone derived from intestinal L cells that stimulates insulin secretion and suppresses appetite and gastrointestinal tract transit [18]. Stimulation of GP-BAR1 by selective agonists stimulates the release of GLP-1 from the murine enteroendocrine cell line STC-1 [17], and GPBAR1-stimulated GLP-1 release improves liver and pancreatic function and glucose tolerance in obese mice [18]. The effects of GP-BAR1 activation on GLP-1 release from STC-1 cells is linked to an increased ATP-to-ADP ratio, which causes the closure of ATP-dependent potassium channels and a subsequent calcium influx, leading to GLP1 secretion [18]. The antidiabetic effects of GP-BAR1 have sparked interest in a possible avenue for the development of novel therapies in type 2 diabetes mellitus (Fig. 3).

GP-BAR1 ligands also exert immunomodulatory functions [19]. The receptor is expressed in macrophages, and its activation reduces macrophage-effector functions triggered by proinflammatory stimuli. In line with the immunosuppressive properties of GP-BAR1 in the immune system, GP-BAR1 serves to protect against colonic inflammation in mice by maintaining integrity of the colonic epithelial barrier [19]. GP-BAR1-deficient mice had an altered architecture of the colonic mucosa at 12 months of age that is characterized by disruption of epithelial tight junctions and a redistribution of zonulin 1 from tight junctions, which results in increased mucosal permeability, a recognized feature of intestinal inflammatory disorders. Following challenge with dextran sodium sulfate, a barrier-breaking agent, GP-BAR1-deficient mice exhibit increased susceptibility to development of colitis, as exemplified by worsened macroscopic and histopathological damage scores compared with wild-type littermates. There is an influx of GP-BAR1-expressing mononuclear cells into the colon of mice exposed to 2,4,6-trinitrobenzenesulfonic acid and patients with Crohn's disease. Ciprofloxacin, a well-known antibiotic, activates GPBAR1 and protects mice against colitis induced by 2,4,6trinitrobenzenesulfonic acid. Whether GP-BAR1 agonists protect against inflammatory bowel disease in patients remains to be determined. However, it is of interest that genetic variations of GP-BAR1 have been linked to development of primary sclerosing cholangitis, a chronic inflammatory disease of the bile duct that is associated with ulcerative colitis [20]. An analysis of the sequence of GPBAR1 in primary sclerosing cholangitis patients and healthy control subjects has identified six nonsynonymous mutations, five of which resulted in a loss of function of GP-BAR1 when expressed in epithelial cell lines [20].

In addition to these effects, GP-BAR1 is important in mediating itching. In mice, peptidergic neurons of dorsal root ganglia and spinal cord that transmit itch and pain express GP-BAR1, which is also expressed by dermal macrophages that contain opioid-like immune reactivity [16]. Bile acids and GP-BAR1-selective agonists induce hyperexcitability of dorsal root ganglia neurons and stimulate the release of itch transmitters, including CGRP and leucine enkephalin. Further, intradermal injection of bile 
acids and a GP-BAR1-selective agonist triggers a scratching behavior caused by CGRP_-and opioid-dependent mechanisms in mice [16]. Thus, bile acids activate GP-BAR1 on sensory nerves, stimulating the release of neuropeptides in the spinal cord that transmit itch. GPBAR1 activation causes analgesia and release of opioid mediators in the spinal cord which might alter the pain perception and contribute to painless jaundice that occurs in cholestatic liver diseases. These "central" effects raise questions on the role of GP-BAR1 in the nervous system and suggest that the receptor might be involved in detecting bile acids that flow through the hematoencephalic barrier or are synthesized directly in the central nervous system. Alternatively, there may be distinct GP-BAR1 agonists in the nervous system, such as neurosteroids that are structurally related to bile acids and are potential agonists of the receptor.

\section{Gastrointestinal injury induced by acetylsalicylic acid nonsteroidal anti-inflammatory drugs}

Acetylsalicylic acid (ASA) and nonselective nonsteroidal anti-inflammatory drugs (NSAIDs) are among the widely used prescription and over-the-counter medications. Despite these drugs exerting a number of beneficial effects, their use causes gastrointestinal side effects, including ulcerations, bleeding, and perforations [21, 22]. Despite ancillary mechanisms having been demonstrated, the basic mode of action of ASA and NSAIDs lies in the inhibition of cyclooxygenases (COXs), a family of enzymes involved in the generation of prostaglandins (PGs) from arachidonic acid [23]. Arachidonic acid is transformed into $\mathrm{PGH}_{2}$ through the activity of COX isoenzymes (i.e., COX-1 and COX-2), and $\mathrm{PGH}_{2}$ is subsequently converted by terminal synthases into biologically active prostanoids, i.e., prostacyclin $\left(\mathrm{PGI}_{2}\right), \mathrm{PGD}_{2}, \mathrm{PGF}_{2 \alpha}, \mathrm{PGE}_{2}$, and thromboxane $\mathrm{A}_{2}$. In particular, the isomerization of $\mathrm{PGH}_{2}$ to $\mathrm{PGE}_{2}$ is catalyzed by three different isomerases: a cytosolic PGE synthase (PGES), membrane-bound PGES-1, and membranebound PGES-2 [4]. The two COX isoforms are the products of different genes. The COX-1 gene is considered a "housekeeping gene," whereas the gene encoding COX-2 is a primary response gene that can be rapidly induced by bacterial endotoxin (lipopolysaccharide), cytokines [such as interleukin- $1 \beta$ and tumor necrosis factor (TNF)- $\alpha$ ], and growth factors [23]. COX-1-dependent prostanoids play an essential homeostatic role in the gastrointestinal tract [21, 22], whereas COX-2-dependent prostanoids exert a dominant role in inflammation.

NSAIDs selective for COX-2 (coxibs) inhibit COX-2dependent $\mathrm{PGE}_{2}$ [24]. In contrast, NSAIDs nonspecifically inhibit both COX-1 and COX-2, and their adverse events in the gastrointestinal tract are attributed to the inhibition of COX-1-derived PGs [24]. Long-term therapy with an NSAID generates adverse gastrointestinal complications ranging from stomach erosions and silent intestinal ulcerations to life-threatening complications such as bleeding and perforation, with an average relative risk of developing a serious gastrointestinal complication in patients exposed to NSAIDs that is fivefold to sixfold higher than that of patients not taking NSAIDs [21, 22]. It is estimated that peptic ulcer bleeding occurs with a frequency of $2-4 \%$ per 100 year-patient treatment, with a mortality rate of $6-10 \%[21,22]$. Deaths related to NSAID-induced gastrointestinal complications have been estimated to account for 15.3 deaths per 100,000 NSAID users in Europe [21, 22]. Cotreatment with the PG analog misoprostol $[25,26]$ or a proton pump inhibitor (PPI) [26] has been demonstrated to be highly effective in reducing the rate of NSAID-related complications in the upper gastrointestinal tract and coprescription of a PPI is the mainstay of current guidelines for prevention of upper gastrointestinal tract complications associated with the use of ASA and NSAIDs worldwide [26].

In addition to these treatments, development of safer NSAID is an important priority $[27,28]$. In this regard, in the last decade two major strategies have emerged as stateof-the-art concepts: (1) the development of selective inhibitors of COX-2, the coxibs (for a review, see [24]); (2) the development of novel chemical entities obtained by the coupling of an NSAIDs to a "donor molecule" that will release $\mathrm{NO}$ and $\mathrm{H}_{2} \mathrm{~S}$ in biological fluids [28, 30-35]. The first members in this class of novel NSAIDs are the socalled NO-NSAIDs, or COX-inhibiting NO donors [28]. Additionally, conjugation of NSAIDs and ASA with phospholipid results in novel chemical entities that spare the gastrointestinal mucosa [36]. In addition, to the upper gastrointestinal tract, NSAIDs can damage the small intestine and the colon [22]. This so-called NSAID enteropathy continues to be greatly underrecognized and is subclinical in the vast majority of cases, and when there are symptoms (including iron-deficiency anemia, occult blood, diarrhea, hypoalbuminemia, and malabsorption), these are largely nonspecific. Unlike for NSAID gastropathy, there are no proven-effective preventive therapies [22, 37, 38].

Coxibs were introduced to the marketplace at the beginning of this century with the promise of gastrointestinal safety [39]. However, although some selective COX-2 inhibitors produce less gastroduodenal damage than NSAIDs, the burden of small intestinal damage remains unchanged.

Additionally, the use of a PPI, while effective at reducing upper gastrointestinal tract complications, does not affect the potential for intestinal injury caused by NSAIDs and coxibs [37]. Thus, NSAID enteropathy remains an 
unsolved problem, and, as such, is driving increasing attention by clinicians and researchers.

\section{FXR and NSAID-induced gastroenteropathy}

By using mice that were deficient for FXR and GP-BAR1, we have demonstrated that ablation of these receptors renders mice highly susceptible to gastric and intestinal damage caused by ASA and NSAIDs [40, 41].

FXR gene ablation alters intestinal and liver physiology in many ways, and FXR-deficient mice display a severe dysregulation of bile acid homeostasis and develop a bile acid dependent liver and intestinal injury and enhanced susceptibility to liver and intestinal carcinogens [42]. FXR gene ablation also alters both innate and adaptive immunity [43-45].

Despite $\mathrm{FXR}^{-1-}$ mice showing normal gastric morphology, they develop severe gastric and intestinal lesions when challenged with ASA or NSAIDs. This enhanced susceptibility is the result of several alterations, including enhanced generation of proinflammatory mediators such as TNF- $\alpha$. This enhanced susceptibility is COX independent because administration of ASA and NSAIDs causes an equal inhibition of COX-1- and COX-2-derived prostanoids, 6-keto-PGF ${ }_{1 \alpha}$ and 6-keto- $\mathrm{PGE}_{2}$, in both the normal phenotype and the $\mathrm{FXR}^{-1-}$ phenotype. Importantly, however, FXR gene ablation impacts on the expression/function of genes involved in generation of $\mathrm{NO}$ and $\mathrm{H}_{2} \mathrm{~S}$, two gaseous mediators that exert a homeostatic function in the gastrointestinal tract. Thus, $\mathrm{FXR}^{-1-}$ mice have reduced expression of endothelial NOS (eNOS) in the gastric mucosa. However, the fact that eNOS deficiency was compensated for by a robust induction of inducible NOS (approximately fivefold in comparison with naive $\mathrm{FXR}^{+/+}$ mice) and that activation of FXR by CDCA attenuates gastric injury in wild-type mice given $N^{\omega}$-nitro-L-arginine methyl ester (a nonselective NOS inhibitor) supports the notion that the gastroprotection exerted by FXR agonism is NO independent [41].

In the past few years, we have shown that cystathionine $\gamma$-lyase (CSE), an enzyme involved in $\mathrm{H}_{2} \mathrm{~S}$ generation from homocysteine and L-cysteine, is selectively targeted by NSAIDs in the gastric mucosa [30]. The mechanistic readout of this interaction is that the stomach of rodents exposed to NSAIDs develops an altered regulation of the cysteine- $\mathrm{H}_{2} \mathrm{~S}$ pathway. Because exogenous $\mathrm{H}_{2} \mathrm{~S}$ attenuates gastric injury caused by NSAIDs despite a continuous inhibition of COXs and NOSs, it has been proposed that $\mathrm{H}_{2} \mathrm{~S}$ is a stand-alone protective mechanism for the gastrointestinal mucosa [30].

CSE is an FXR-regulated gene [46, 47]. Indeed, the FXR promoter contains an FXR-responsive element in its $5^{\prime}$ flanking region whose activation regulates the level of expression of CSE, messenger RNA (mRNA) and protein in the liver [46]. Consistent with this finding, the gastric expression of CSE mRNA and CSE activity were drastically reduced in $\mathrm{FXR}^{-1-}$ mice. Together with the fact that administration of ASA reduces the gastric expression and activity of CSE in wild-type mice and that protection against injury caused by ASA by GW4064, a selective FXR ligand of nonsteroidal structure, associated with a robust induction of CSE expression and activity, whereas inhibition of CSE with DL-propargylglycine attenuates protection afforded by FXR agonists, it appears that a dysregulated expression of CSE in the gastrointestinal mucosa makes an important contribution to the enhanced susceptibility of gastrointestinal mucosa to damage caused by ASA and NSAIDs in $\mathrm{FXR}^{-1-}$ mice [41].

Despite an impairment of FXR-CSE- $\mathrm{H}_{2} \mathrm{~S}$ pathways providing a sound explanation for the enhanced susceptibility of the gastrointestinal tract to ASA and NSAIDs in mice harboring a disrupted FXR gene, alternative explanations warrant considerations. Importantly, FXR-deficient mice display a severe alteration in bile acid and phospholipid homeostasis [42].

There is robust evidence to support the notion that an impaired bile acid to phospholipid ratio contributes to the damage caused by ASA/NSAIDs [48-51]. Indeed, bile salts at high concentrations are detergent molecules that solubilize hydrophobic lipids (cholesterol) and phospholipids in micelles, allowing bile formation, cholesterol disposal, and intestinal lipid absorption. Secondary bile acids, however, are directly cytotoxic, and their toxic activity on cells is strongly attenuated by their combination with phospholipids. Phospholipids bind bile salts to form mixed micelles, a condition that attenuates bile salt detergency $[49,51]$. Although development of NSAID gastroenteropathy requires bile acids, phospholipids greatly attenuate gastric and intestinal injury caused by ASA and NSAIDs. Thus, phosphatidylcholine attenuates gastrointestinal toxicity of ASA in COX-1 knockout mice, and NSAID enteropathy can be rescued by phospholipids. Further, some NSAIDs, such as indomethacin and to a lesser extent diclofenac, reverse the protective effect phospholipids exert in vitro on intestinal cells exposed to high concentrations of bile acids [49].

These observations suggest that bile salts either enhance the intrinsic cytotoxicity of NSAIDs or interact with them to form membrane-damaging molecular species. In contrast, phospholipid species attenuate NSAID cytotoxicity via an unknown mechanism, possibly by preventing the direct contact between these drugs and intestinal membranes. Consistent with this view, Prakash and Gorfe [52] have recently provided evidence that $\mathrm{CA}$ and indomethacin spontaneously form mixed micelles, with the hydrophobic 
face of $\mathrm{CA}$ and the hydrophobic region of indomethacin forming the core. At high concentrations indomethacin causes the formation of stable aggregates that contain a progressively larger number of indomethacin molecules. Addition of palmitoyloleylphosphatidylcholine causes the formation of ternary mixed micelles in which CA and indomethacin are distributed almost uniformly on the surface such that intra-CA, intra-indomethacin, and $\mathrm{CA}-$ indomethacin interactions are minimized. This study suggests that highly charged CA-indomethacin binary micelles could be deleterious for intestinal epithelia, and that phospholipids reduce the ability of a CA-indomethacin mixture to aggregate [52]. This may partly explain the lower toxicity of phospholipid-conjugated NSAIDs.

These findings suggest that NSAIDs exert their ulcerogenic effects in the small intestine in part by decreasing the protection that phospholipid species exert against the direct injurious activity of bile acid-NSAID aggregates, thus explaining why only NSAIDs that undergo an enterohepatic circulation cause intestinal injury. Indeed, some NSAIDs undergo a robust hepatic metabolism leading to the formation of acyl glucuronides. These NSAID metabolites are excreted with the bile and appear to be toxic for intestinal epithelia.

Secretion of phospholipids by hepatocytes in the bile requires the activity of a family of transporters, including multidrug resistance protein 2 and multidrug resistance protein 3 [53-56]. Importantly, FXR controls bile salt homeostasis in hepatocytes and enhances the expression of genes involved in phospholipid secretion, thus coupling biliary secretion of bile salts and phospholipids. Importantly, FXR-deficient mice are known to produce smaller amounts of phospholipids [42], and alteration of this critical component might also account for enhanced toxicity of ASA and NSAIDs in the intestine. Thus, an impaired secretion of phospholipids might contribute to explaining the enhanced susceptibility of $\mathrm{FXR}^{-1-}$ mice to injury caused by ASA and NSAIDs, providing additional support to the theory that targeting phospholipids might be an interesting possibility to minimize intestinal injury caused by ASA and NSAIDs.

\section{FXR is a potential mediator of beneficial effects of licorice extracts in the stomach}

Additional support for the role of FXR as a gene involved in gastric protection comes from the finding that a natural product, widely used in popular medicine as a gastric protecting agent, glycyrrhizic acid, acts, at least in part, through an FXR-related mechanism.

Licorice root extracts have been used widely to promote the healing of peptic ulcers. Glycyrrhizic acid, the main active ingredient of licorice root extracts [57-59], is a triterpenoid glycosidic saponin used as a sweetener. Glycyrrhizic acid is converted in glycyrrhetinic acid in the small intestine by the activity of the intestinal microbiota and undergoes an extensive metabolic biotransformation in the liver [57-59]. Thus, glycyrrhizic acid is not detectable in the blood. Data from our laboratory demonstrate that glycyrrhizic acid activates FXR, whereas neither glycyrrhetinic acid nor carbenoxolone, a drug widely used in the past for treating peptic ulcer, are endowed with an FXR agonistic activity despite having structural similarities (Fig. 4).

The results shown in Fig. 4 demonstrate that glycyrrhizic acid transactivates FXR, despite it being significantly less potent than CDCA. Thus, exposure of HepG2 cells overexpressing FXR to this agent caused an eightfold to tenfold induction of FXR transcription, as expressed as relative luciferase units versus $\beta$-galactosidase in the luciferase-reporter assay. In contrast, glycyrrhetinic acid as well as carbenoxolone failed to transactivate FXR. As illustrated in Fig. 5, treating $\mathrm{FXR}^{+/+}$mice with glycyrrhizic acid (40 mg/kg intraperitoneally) effectively attenuated gastric injury caused by ASA. The effect was COX independent. Additionally, no changes were found in the level of expression of eNOS and inducible NOS mRNAs. Exposure to glycyrrhizic acid, however, increases the expression of FXR in the gastric mucosa, and this change associated with a twofold increase in the expression of CSE mRNA. Importantly, protection exerted by glycyrrhizic acid was attenuated in $\mathrm{FXR}^{-1-}$ mice (Fig. 5).

Despite their beneficial effects on ulcer healing, extracts of licorice roots are known to produce severe hypertension and hypokalemia [57-59]. This mineralcorticoid-like syndrome is primarily caused by the inhibition of $11 \beta$ hydroxysteroid dehydrogenase, an enzyme that inactivates intracellular glucocorticoids in mineralocorticoid-responsive organs, such as the kidney, increasing relative levels of cortisol, which stimulates aldosterone receptors, leading to a functional mineralocorticoid excess [57-59]. Our data indicate that in addition to inhibition of $11 \beta$-hydroxysteroid dehydrogenase or activation of estrogen receptors or peroxisome-proliferator-activated receptors [60], glycyrrhizic acid might also function as an FXR ligand/ modulator.

\section{GP-BAR1 and NSAIDs}

GP-BAR1 is required for maintenance of gastrointestinal mucosal integrity and, once again, this protective effect is PG independent. This contention emerges from the results of studies conducted in GP-BAR $1^{-1-}$ mice [40]. Despite these mice showing normal gastric morphology, they 
A

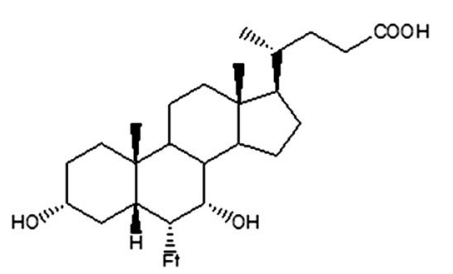

CDCA

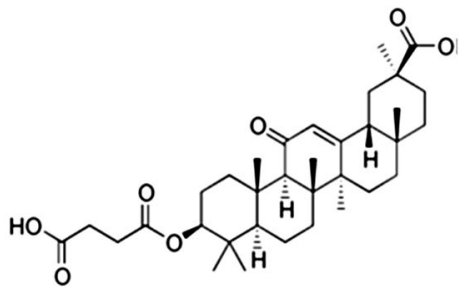

Carbenoxolone

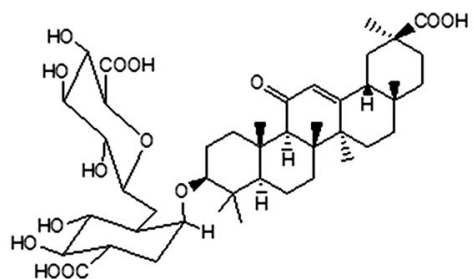

Glycyrrhizic acid

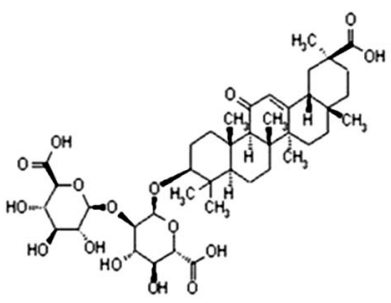

B

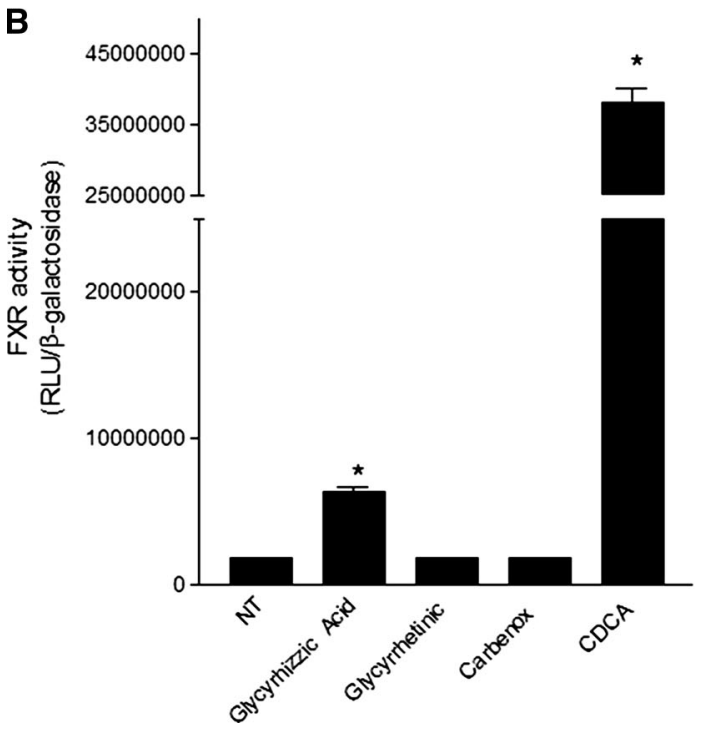

Fig. 4 Glycyrrizic acid, a licorice root extract, is a farnesoid $\mathrm{X}$ receptor $(F X R)$ ligand. a Structures of chenodeoxycholic acid $(C D C A)$, carbenoxolone, glycyrrhetinic acid, and glycyrrhizic acid, the main ingredient of licorice root (Glycyrrhiza glabra) extracts. b Transactivation of FXR by glycyrrhizic acid, glycyrrhetinic acid, carbenoxolone, and CDCA in HepG2 cells, a hepatoma cell line, transfected with $\mathrm{FXR} /$ retinoid $\mathrm{X}$ receptor reporter vector. Cells were incubated for $24 \mathrm{~h}$ with the indicated agents at a concentration of

develop severe injury when challenged with ASA. This enhanced susceptibility is COX independent because expression of COX-1 and COX-2 mRNAs in the gastric mucosa was regulated in a similar manner in wild-type and GP-BAR $1^{-1-}$ mice, and the magnitude of the suppressive effect exerted by ASA on the formation $\mathrm{PGE}_{2}$ was comparable in the two mouse strains. The enhanced susceptibility of mice harboring a disrupted GP-BAR1 to COXinhibiting agents extends beyond the stomach, because GP-

\section{Glycyrrhetinic acid}

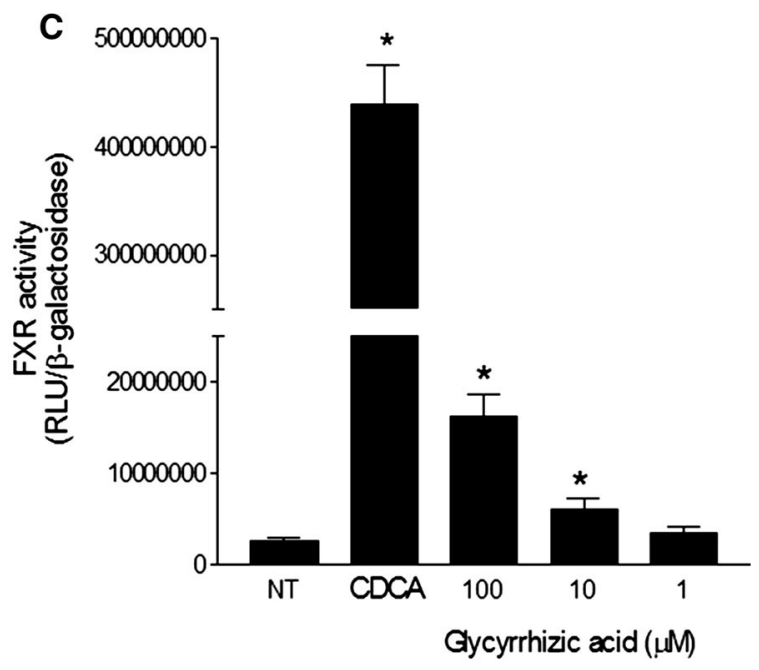

$10 \mu \mathrm{M}$. Vertical bars represents FXR transactivation measured as relative luciferase units $(R L U)$ normalized in comparison with $\beta$ galactosidase activity. c Concentration response curve of FXR activation by glycyrrhizic acid. Vertical bars represent FXR transactivation. The data shown are the mean \pm the standard error of four to five experiments. Asterisk $P<0.05$ versus untreated cells $(n=4), N T$ not treated

$\mathrm{BAR}^{-1-}$ mice also severe develop intestinal injury in response to naproxen, a validated model of intestinal damage.

In the search for a mechanism that could support this enhanced susceptibility, we have investigated whether GPBAR1 regulates $\mathrm{NO}$ and $\mathrm{H}_{2} \mathrm{~S}$ generation. Previous studies have shown that bile acids increase the expression of eNOS by a GP-BAR1 and cyclic AMP (cAMP)-dependent mechanism in isolated sinusoid endothelial cells [61], a 
A
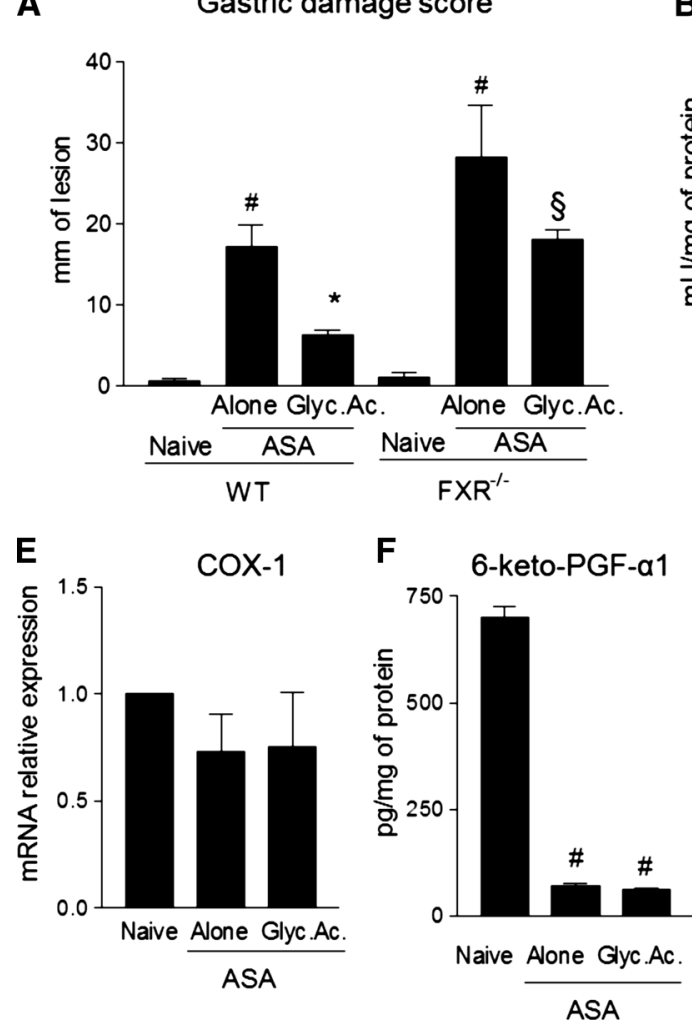

G
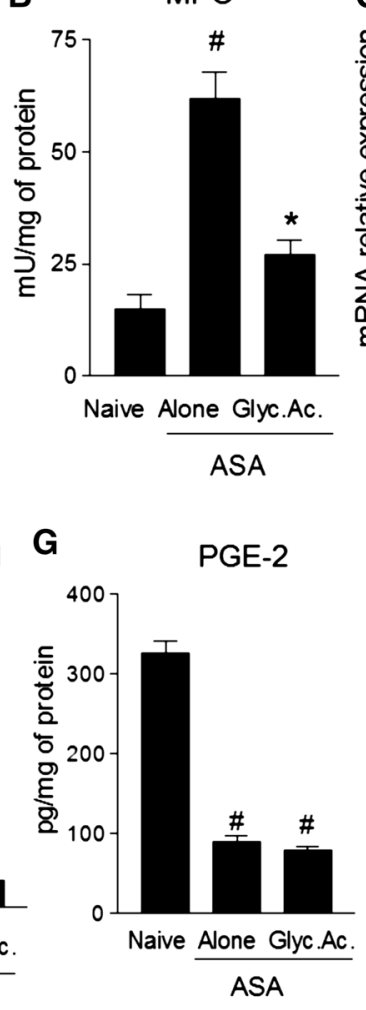

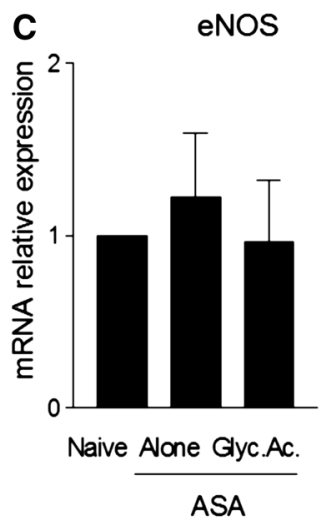

D iNOS
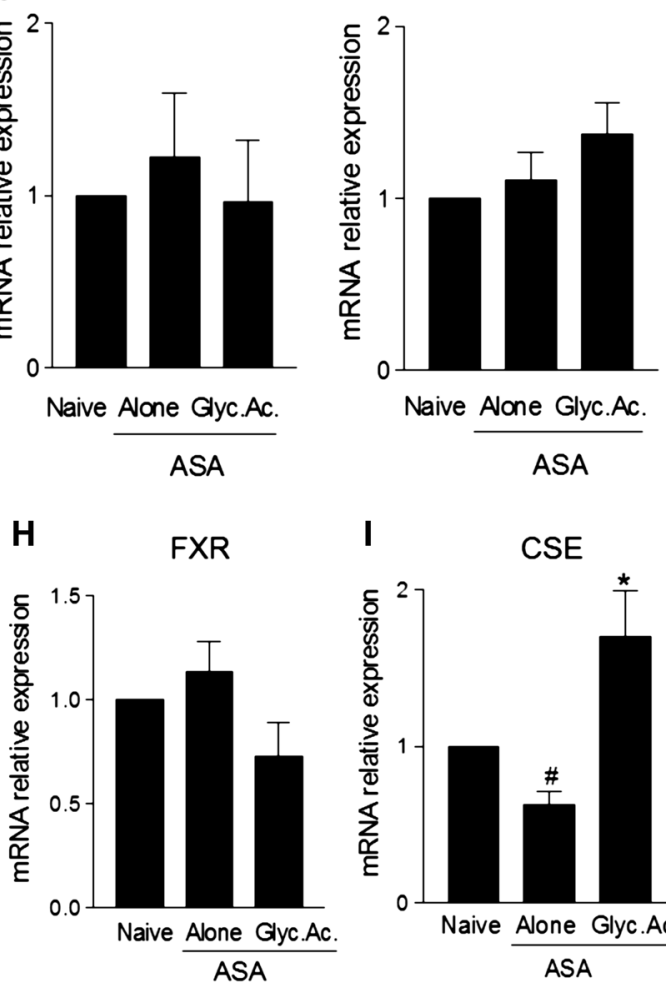

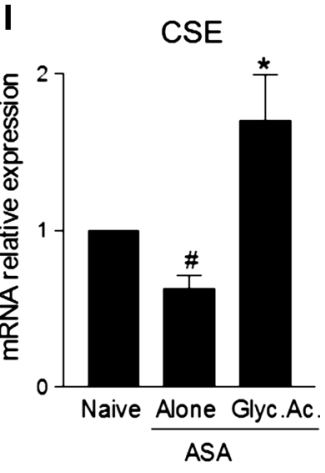

Fig. 5 Glycyrrhizic acid protects against gastric injury caused by acetylsalicylic acid $(A S A)$ in a cyclooxygenase $(C O X)$-independent and farnesoid $\mathrm{X}$ receptor $(F X R)$-dependent manner and by stimulating cystathionine $\gamma$-lyase (CSE) expression. a Administration of glycirrhizic acid attenuates gastric injury caused by dosing wild-type mice with ASA. However, protection exerted by glycirrhizic acid is partially reduced by FXR gene ablation. ASA was administered to mice at $50 \mathrm{mg} / \mathrm{kg}$ by gavage alone or in combination with glycerrhizic acid $(40 \mathrm{mg} / \mathrm{kg})$ and the mice were killed $3 \mathrm{~h}$ later. The severity of gastric damage is expressed as the gastric damage score, i.e., the sum of linear ulcerations found in the stomach and expressed in millimeters. The data shown are the mean \pm the standard error for five to seven mice per group. b-i Assessment of biochemical markers of gastric damage in wild-type mice exposed to ASA alone or in combination with GW4064, a nonsteroidal FXR ligand. The data shown are the mean \pm the standard error for five to seven mice per group. ${ }^{\#} P<0.05$ versus naïve mice, ${ }^{*} P<0.05$ versus ASA alone, paragraph sign, eNOS endothelial NO synthase, Glyc .Ac. glycerrhizic acid, $i N O S$ inducible NO synthase, MPO myeloperoxidase, $m R N A$ messenger mRNA, $P G E$ prostaglandin E, $P G F$ prostaglandin F, WT wild type

monocytes, ciprofloxacin increases cAMP concentrations and attenuates TNF- $\alpha$ release in a GP-BAR1-dependent manner [62]. Furthermore, ciprofloxacin abrogates signs and symptoms of inflammation in mouse models of colitis by a GP-BAR1-dependent mechanism. Betulinic acid is a natural triterpene and potent GP-BAR1 agonist [62]. By using these two agents, we have shown that GP-BAR1 activation rescues wild-type mice from gastric injury caused by ASA and that this protective effect relies on the regulation of $\mathrm{CSE} /$ cystathionine $\beta$-synthase expression in the gastric mucosa. Support for this concept comes from the finding that coadministration of DL-propargylglycine and ciprofloxacin reverses the protective effects exerted by ciprofloxacin. Together, these data support the notion that a dysregulated expression of CSE in the gastrointestinal mucosa makes an important contribution to the enhanced susceptibility of GP-BAR $1^{-1-}$ mice to damage caused by ASA and NSAIDs. 
Gastric expression of membrane (MUCl) and secreted (MUC5AC, MUC6) mucins is altered in models of reactive gastropathy [62]. Importantly, $M U C 1$ expression is reduced in the stomach of patients exposed to NSAIDs. The findings that GP-BAR $1^{-/-}$mice react to exposure to ASA by a marked reduction of $M U C 1$ expression and that ciprofloxacin increases the expression of this gene in wild-type mice challenged with ASA highlight a possible regulatory role for GP-BAR1 in MUC1 expression.

\section{Conclusions}

It is well known that bile acids might function as barrierbreaking agents, thus enhancing gastric and intestinal injury caused by ASA and NSAIDs. Because bile acids, especially secondary bile acids, are cytotoxic, their intracellular concentration is tightly regulated by the intervention of a family of NRs (FXR, constitutive androstane receptor, and pregnane $\mathrm{X}$ receptor) that orchestrate their import, conjugation, and excretion [1]. Bile acids, in turn, activate an array of receptors collectively known as bile acid activated receptors (BARs). Activation of FXR and GP-BAR1 modulates the expression/activity of genes involved in the production of mediators essential for maintenance of intestinal integrity. Importantly, both receptors converge on regulation of eNOS and CSE, i.e., two genes required for the generation of $\mathrm{NO}$ and $\mathrm{H}_{2} \mathrm{~S}$, by genomic and nongenomic effects. $\mathrm{FXR}^{-1-}$ mice develop a number of intestinal and liver abnormalities owing to the accumulation of bile acids at toxic concentrations. GP$\mathrm{BAR}^{-1-}$ mice had a reduced bile acid pool but, because the liver expression of $C Y P 8 B 1$, a gene that regulates the $\mathrm{CA}$ to CDCA ratio is increased, they have higher levels of CA. Thus, the fact that mice lacking FXR and GP-BAR1 are more prone to develop gastrointestinal injury in response to ASA/NSAIDs underlines that BARs are essential in maintaining gastrointestinal homeostasis. Furthermore, because FXR and GP-BAR1 activation by nonbile acid agonists (GW4064, ciprofloxacin, and betulinic acid) rescues organs from injury caused by ASA and NSAIDs, these receptors could be exploited to protect the gastrointestinal tract in a wide array of pathophysiological settings.

The fact that FXR and GP-BAR1 agonists are protective against intestinal damage caused by NSAIDs does not contradict the finding that bile salts per se are detergent molecules that might directly injure the intestine. Indeed, ablation of BARs leads to dysregulation of bile acid and phospholipid homeostasis, which might contribute to enhanced susceptibility to intestinal injury.

The FXR and GP-BAR1-NO- $\mathrm{H}_{2} \mathrm{~S}$ pathways could be exploited therapeutically to protect the intestinal mucosa.
Importantly, although a number of approaches are available to effectively protect the gastric mucosa against damage caused by ASA and NSAIDs, the same is not true for the intestinal injury caused by these agents. Intestinal complications caused by NSAIDs and coxibs are not prevented by cotreatment with PPIs, and the use of some coxibs is associated with an increased risk of cardiovascular ischemic events. In this context, development of FXR-GPBAR1 agonists $[62,63]$ to protect the intestinal mucosa might have relevance in the treatment of patients taking ASA or NSAIDs that are at high risk of developing gastrointestinal and cardiovascular complications for whom coxibs cannot be recommended.

Conflict of interest The authors declare that they have no conflict of interest.

\section{References}

1. Fiorucci S, Zampella A, Distrutti E. Development of FXR, PXR and CAR agonists and antagonists for treatment of liver disorders. Curr Top Med Chem. 2012;12:605-24.

2. Fiorucci S, Cipriani S, Baldelli F, et al. Bile acid-activated receptors in the treatment of dyslipidemia and related disorders. Prog Lipid Res. 2010;49:171-85.

3. Fiorucci S, Mencarelli A, Palladino G, et al. Bile-acid-activated receptors: targeting TGR5 and farnesoid-X-receptor in lipid and glucose disorders. Trends Pharmacol Sci. 2009;30:570-80.

4. Fiorucci S, Rizzo G, Donini A, et al. Targeting farnesoid X receptor for liver and metabolic disorders. Trends Mol Med. 2007;13:298-309.

5. Swanson HI, Wada T, Xie W, et al. Role of nuclear receptors in lipid dysfunction and obesity-related diseases. Drug Metab Dispos. 2013;41:1-11.

6. Fiorucci S, Mencarelli A, Distrutti E, et al. Farnesoid X receptor: from medicinal chemistry to clinical applications. Future Med Chem. 2012;4:877-91.

7. Kong B, Wang L, Chiang JY, et al. Mechanism of tissue-specific farnesoid $\mathrm{X}$ receptor in suppressing the expression of genes in bile-acid synthesis in mice. Hepatology. 2012;56:1034-43.

8. Wang L, Lee YK, Bundman D, et al. Redundant pathways for negative feedback regulation of bile acid production. Dev Cell. 2002;2:721-31.

9. Eloranta JJ, Meier PJ, Kullak-Ublick GA. Coordinate transcriptional regulation of transport and metabolism. Methods Enzymol. 2005;400:511-30.

10. Kullak-Ublick GA, Stieger B, Meier PJ. Enterohepatic bile salt transporters in normal physiology and liver disease. Gastroenterology. 2004;126:322-42.

11. Owen BM, Mangelsdorf DJ, Kliewer SA. Tissue-specific actions of the metabolic hormones FGF15/19 and FGF21. Trends Endocrinol Metab. 2014. doi:10.1016/j.tem.2014.10.002.

12. Inagaki T, Choi M, Moschetta A, et al. Fibroblast growth factor 15 functions as an enterohepatic signal to regulate bile acid homeostasis. Cell Metab. 2005;2:217-25.

13. Lieu T, Jayaweera G, Bunnett NW. GPBA: a GPCR for bile acids and an emerging therapeutic target for disorders of digestion and sensation. Br J Pharmacol. 2014;171:1156-66.

14. Poole DP, Godfrey C, Cattaruzza F, et al. Expression and function of the bile acid receptor GP-BAR1 (TGR5) in the murine enteric nervous system. Neurogastroenterol Motil. 2010;22:814-25. 
15. Alemi F, Poole DP, Chiu J, et al. The receptor TGR5 mediates the prokinetic actions of intestinal bile acids and is required for normal defecation in mice. Gastroenterology. 2013;144:145-54.

16. Lieu T, Jayaweera G, Zhao P, et al. The bile acid receptor TGR5 activates the TRPA1 channel to induce itch in mice. Gastroenterology. 2014;147:1417-28.

17. Camilleri M, Vazquez-Roque MI, Carlson P, et al. Association of bile acid receptor TGR5 variation and transit in health and lower functional gastrointestinal disorders. Neurogastroenterol Motil. 2011;23:995-9.

18. Katsuma S, Hirasawa A, Tsujimoto G. Bile acids promote glucagon-like peptide-1 secretion through TGR5 in a murine enteroendocrine cell line STC-1. Biochem Biophys Res Commun. 2005;329:386-90.

19. Cipriani S, Mencarelli A, Chini MG, et al. The bile acid receptor GPBAR-1 (TGR5) modulates integrity of intestinal barrier and immune response to experimental colitis. PLoS One. 2011. doi:10.1371/journal.pone.0025637.

20. Hov JR, Keitel V, Laerdahl JK, et al. Mutational characterization of the bile acid receptor TGR5 in primary sclerosing cholangitis. PLoS One. 2010. doi:10.1371/journal.pone.0012403.

21. Laine L. Review article: gastrointestinal bleeding with low-dose aspirin—what's the risk? Aliment Pharmacol Ther. 2006;24:897908.

22. Laine L, Smith R, Min K, et al. Systematic review: the lower gastrointestinal adverse effects of non-steroidal anti-inflammatory drugs. Aliment Pharmacol Ther. 2006;24:751-67.

23. Takeuchi K. Pathogenesis of NSAID-induced gastric damage: importance of cyclooxygenase inhibition and gastric hypermotility. World J Gastroenterol. 2012;18:2147-60.

24. Grosser T, Yu Y, Fitzgerald GA. Emotion recollected in tranquility: lessons learned from the COX-2 saga. Annu Rev Med. 2010;61:17-33.

25. Laine L, Jensen DM. Management of patients with ulcer bleeding. Am J Gastroenterol. 2012;107:345-60.

26. Hawkey CJ, Karrasch JA, Szczepañski L, et al. Omeprazole compared with misoprostol for ulcers associated with nonsteroidal anti-inflammatory drugs. N Engl J Med. 1998;338:72734.

27. Fiorucci S. Prevention of nonsteroidal anti-inflammatory druginduced ulcer: looking to the future. Gastroenterol Clin North Am. 2009;38:315-32.

28. Fiorucci S, Distrutti E, de Lima OM, et al. Relative contribution of acetylated cyclo-oxygenase (COX)-2 and 5-lipooxygenase (LOX) in regulating gastric mucosal integrity and adaptation to aspirin. FASEB J. 2003;17:1171-3.

29. Fiorucci S, Antonelli E, Distrutti E, Rizzo G, et al. Inhibition of hydrogen sulfide generation contributes to gastric injury caused by anti-inflammatory nonsteroidal drugs. Gastroenterology. 2005;129:1210-24.

30. Santucci L, Wallace J, Mencarelli A, et al. Different sensitivity of lamina propria T-cell subsets to nitric oxide-induced apoptosis explains immunomodulatory activity of a nitric oxide-releasing derivative of mesalamine in rodent colitis. Gastroenterology. 2005;128:1243-57.

31. Fiorucci S, Mencarelli A, Meneguzzi A, et al. Co-administration of nitric oxide-aspirin (NCX-4016) and aspirin prevents platelet and monocyte activation and protects against gastric damage induced by aspirin in humans. J Am Coll Cardiol. 2004;44:635-41.

32. Fiorucci S, Santucci L, Wallace JL, et al. Interaction of a selective cyclooxygenase-2 inhibitor with aspirin and NO-releasing aspirin in the human gastric mucosa. Proc Natl Acad Sci U S A. 2003;100:10937-41.

33. Fiorucci S, Santucci L, Gresele P, et al. Gastrointestinal safety of NO-aspirin (NCX-4016) in healthy human volunteers: a proof of concept endoscopic study. Gastroenterology. 2003;124(3):600-7.
34. Wallace JL, Ignarro LJ, Fiorucci S. Potential cardioprotective actions of no-releasing aspirin. Nat Rev Drug Discov. 2002;1: 375-82.

35. Cryer B, Bhatt DL, Lanza FL, et al. Low-dose aspirin-induced ulceration is attenuated by aspirin-phosphatidylcholine: a randomized clinical trial. Am J Gastroenterol. 2011;106:272-7.

36. Marlicz W, Loniewski I, Grimes DS, et al. Nonsteroidal antiinflammatory drugs, proton pump inhibitors, and gastrointestinal injury: contrasting interactions in the stomach and small intestine. Mayo Clin Proc. 2014;89:1699-709.

37. Blackler RW, Motta JP, Manko A, et al. Hydrogen sulphide protects against NSAID-enteropathy through modulation of bile and the microbiota. Br J Pharmacol. 2014. doi:10.1111/bph. 12961.

38. Atukorala I, Hunter DJ. Valdecoxib: the rise and fall of a COX-2 inhibitor. Expert Opin Pharmacother. 2013;14:1077-86.

39. Cipriani S, Mencarelli A, Bruno A, et al. Activation of the bile acid receptor GPBAR1 protects against gastrointestinal injury caused by non-steroidal anti-inflammatory drugs and aspirin in mice. Br J Pharmacol. 2013;168:225-37.

40. Fiorucci S, Mencarelli A, Cipriani S, et al. Activation of the farnesoid-X receptor protects against gastrointestinal injury caused by non-steroidal anti-inflammatory drugs in mice. $\mathrm{Br} \mathrm{J}$ Pharmacol. 2011;164:1929-38.

41. Sinal CJ, Tohkin M, Miyata M, et al. Targeted disruption of the nuclear receptor FXR/BAR impairs bile acid and lipid homeostasis. Cell. 2000;102:731-44.

42. Mencarelli A, Renga B, Migliorati M, et al. The bile acid sensor farnesoid $\mathrm{X}$ receptor is a modulator of liver immunity in a rodent model of acute hepatitis. J Immunol. 2009;183:6657-66.

43. Vavassori P, Mencarelli A, Renga B, et al. The bile acid receptor FXR is a modulator of intestinal innate immunity. J Immunol. 2009;183:6251-61.

44. Fiorucci S, Cipriani S, Mencarelli A, et al. Counter-regulatory role of bile acid activated receptors in immunity and inflammation. Curr Mol Med. 2010;10:579-95.

45. Renga B, Mencarelli A, Migliorati M, et al. Bile-acid-activated farnesoid $\mathrm{X}$ receptor regulates hydrogen sulfide production and hepatic microcirculation. World J Gastroenterol. 2009;15:2097108.

46. Renga B. Hydrogen sulfide generation in mammals: the molecular biology of cystathionine- $\beta$ - synthase (CBS) and cystathionine- $\gamma$ lyase (CSE). Inflamm Allergy Drug Targets. 2011;10:85-91.

47. Venneman NG, Petruzzelli M, van Dijk JE, et al. Indomethacin disrupts the protective effect of phosphatidylcholine against bile saltinduced ileal mucosa injury. Eur J Clin Investig. 2006;36:105-12.

48. Barrios JM, Lichtenberger LM. Role of biliary phosphatidylcholine in bile acid protection and NSAID injury of the ileal mucosa in rats. Gastroenterology. 2000;118:1179-86.

49. Prakash P, Sayyed-Ahmad A, Zhou Y, et al. Aggregation behavior of ibuprofen, cholic acid and dodecylphosphocholine micelles. Biochim Biophys Acta. 2012;1818:3040-7.

50. Lanza FL, Marathi UK, Anand BS, et al. Clinical trial: comparison of ibuprofen-phosphatidylcholine and ibuprofen on the gastrointestinal safety and analgesic efficacy in osteoarthritic patients. Aliment. Pharmacol Ther. 2008;28:431-42.

51. Prakash P, Gorfe AA. Phosphatidylcholine attenuates aggregation of nonsteroidal anti-inflammatory drugs with bile acid. Biochemistry. 2013;52:7461-9.

52. Zhou Y, Dial EJ, Doyen R, et al. Effect of indomethacin on bile acid-phospholipid interactions: implication for small intestinal injury induced by nonsteroidal anti-inflammatory drugs. Am J Physiol Gastrointest Liver Physiol. 2010;298:G722-31.

53. Huang L, Zhao A, Lew JL, et al. Farnesoid X receptor activates transcription of the phospholipid pump MDR3. J Biol Chem. 2003;278:51085-90. 
54. Guo GL, Lambert G, Negishi M, et al. Complementary roles of farnesoid $X$ receptor, pregnane $X$ receptor, and constitutive androstane receptor in protection against bile acid toxicity. $\mathrm{J}$ Biol Chem. 2003;278:45062-71.

55. Urizar NL, Dowhan DH, Moore DD. The farnesoid X-activated receptor mediates bile acid activation of phospholipid transfer protein gene expression. J Biol Chem. 2000;275:39313-7.

56. Kratschmar DV, Vuorinen A, Da Cunha T, et al. Characterization of activity and binding mode of glycyrrhetinic acid derivatives inhibiting 11ß-hydroxysteroid dehydrogenase type. J Steroid Biochem Mol Biol. 2011;125:129-42.

57. Ferrari P. The role of $11 \beta$-hydroxysteroid dehydrogenase type 2 in human hypertension. Biochim Biophys Acta. 2010;1802:117887.

58. Schröfelbauer B, Raffetseder J, Hauner M, et al. Glycyrrhizin, the main active compound in liquorice, attenuates pro-inflammatory responses by interfering with membrane-dependent receptor signalling. Biochem J. 2009;421:473-82.

59. Mae T, Kishida H, Nishiyama T, et al. A licorice ethanolic extract with peroxisome proliferator-activated receptor-gamma ligand- binding activity affects diabetes in KK-Ay mice, abdominal obesity in diet-induced obese C57BL mice and hypertension in spontaneously hypertensive rats. J Nutr. 2003;133:3369-77.

60. Keitel V, Reinehr R, Gatsios P, et al. The G-protein coupled bile salt receptor TGR5 is expressed in liver sinusoidal endothelial cells. Hepatology. 2007;45:695-704.

61. Cipriani S, Mencarelli A, Chini MG, et al. The bile acid receptor GPBAR-1 (TGR5) modulates integrity of intestinal barrier and immune response to experimental colitis. PLoS One. 2011;6: e25637.

62. Sepe V, Renga B, Festa C, et al. Modification on ursodeoxycholic acid (UDCA) scaffold. discovery of bile acid derivatives as selective agonists of cell-surface G-protein coupled bile acid receptor 1 (GP-BAR1). J Med Chem. 2014;57:7687-701.

63. Festa C, Renga B, D'Amore C, et al. Exploitation of cholane scaffold for the discovery of potent and selective farnesoid $\mathrm{X}$ receptor (FXR) and G-protein coupled bile acid receptor 1 (GPBAR1) ligands. J Med Chem. 2014;57:8477-95. 